\title{
The pathogenesis and classification of polar tuberculoid leprosy
}

\author{
D S RIDLEY \\ Hospital for Tropical Diseases, London NW1 OPE
}

Received for publication 5 May 1981

\begin{abstract}
Summary Skin biopsies received from about 1,500 patients of varied ethnic and geographical origins produced 26 cases that fell within the polar tuberculoid (TT) group on the strictest definition, and a further 18 cases that might be considered as TT on histological and immunological grounds.

The 44 cases were of 2 broad types. Nearly half were characterized by many lymphocytes but few other histological features, with no severe nerve involvement, no signs of reaction and good clinical-histological correlation. The remainder were characterized by severe nerve involvement or erosion of the epidermis and often by signs of reaction, all of which are associated with high lymphocyte transformation values; many of these cases were clinically BT.

There was a fairly sharp distinction between these 2 types, with an intermixing of features only in cases that were not truly polar. There was also a partial geographical separation of the 2 types. The first appeared to represent primary lesions with high cell-mediated immunity; the second to have evolved through reactions associated with delaye
\end{abstract}

\section{Introduction}

The history of the classification of tuberculoid leprosy is reviewed by Noussitou, ${ }^{1}$ who points to the need for a system which is prognostically reliable enough to serve as the basis for chemotherapeutic trials. It could only be evaluated by reference to the natural outcome of the infection, but whereas Souza Lima and Souza Campos, ${ }^{2}$ prior to the introduction of sulphones, were able to follow the natural course of 979 infections for periods up to 5 years, nothing like this is possible today. In the present paper we return to the subject of histology in relation to immunological function, partly for the sake of such value as it may have for classification, but mainly because polar tuberculoid 
leprosy is a subject of immunological interest in its own right, and the only form of established leprosy in which the natural healing processes may be observed.

The only convenient immunological parameter for general use is the lepromin reaction. The original description of the TT group was based partly on it, ${ }^{3}$ and it was hoped that it might be sufficiently reliable for use in individual patients. ${ }^{4}$ However, these results were based on a small number of TT patients. The lepromin reaction is still possibly the best of the immunological tests, ${ }^{5}$ but there is appreciable variation ${ }^{2}$ and overlap between TT and BT patients. ${ }^{6}$ The introduction of the lymphocyte transformation test (LTT) provided a new parameter which confirmed the spectrum, ${ }^{7,8}$ but there were serious individual discrepancies partly due to the preponderant influence of reactions ${ }^{9}$ and partly due to serum factors. ${ }^{10}$

The original histological definition of the TT group was based only on lymphocytes and epithelioid cells, ${ }^{3}$ and in the light of the LTT results it was broadened to take account of the LTT-associated histological features ${ }^{4}$ which probably represent delayed hypersensitivity. ${ }^{11}$ The subsequent demonstration that lymphocytes in lesions were not closely correlated with LTT values ${ }^{9}$ raised the possibility that there were in fact 2 sorts of TT patient, one in whom cell-mediated immunity predominated, the other delayed hypersensitivity. ${ }^{11}$ The subject is explored further in the present histopathological analysis of a larger series of patients. It is regrettable that the need to include cases from as many sources as possible precluded the possibility of full clinical or immunological correlation, but all available data is included.

\section{Material and methods}

All biopsies of near-polar tuberculoid leprosy were reviewed from a number of sources as follows; the figures refer to the total intake of leprosy biopsies. (1) Biopsies received from the Medical Research Council Unit at Sungei Buloh, Malaysia, during the 2-year period 1979-80; about 400 biopsies. (2) Biopsies received from the Medical Research Council Unit at Addis Ababa during a 2-year period, which covered a prospective trial of borderline reversal reactions during which lymphocyte transformation tests were carried out; ${ }^{9}$ about 400 biopsies. (3) Biopsies received from the Karimui, Papua New Guinea, which were the subject of a study of early lesions in $1973,{ }^{12}$ together with a few more recent cases; about 100 biopsies. (4) Biopsies from a collection at the Hospital for Tropical Diseases, which included amongst others a number of cases of European or Eurasian origin; about 100 selected cases. (5) Biopsies received and reported on by Dr D J Harman at the Leprosy Study Centre during a 2-year period before the material was transferred to this Hospital in 1980; this material was of world-wide distribution; about 800 biopsies. 
From this total of about 1,800 biopsies, representing probably about 1,500 cases, 44 cases were found which could be considered to fall within the TT group as previously defined ${ }^{4}$ or to show in high degree some of the features on which that definition was based. With 1 or 2 exceptions they had received no previous treatment, and they were not in overt reaction as all such cases were excluded.

The various histological features were indexed on an arbitrary scale from \pm to ++ . A search was made of two or three suitably stained sections for acid-fast bacilli, which were either scanty ( 1 or 2 bacilli) or absent. The histology has already been amply illustrated. ${ }^{4,13}$

\section{Results and discussion}

\section{HISTOLOGICAL ANALYSIS}

All skin biopsies of tuberculoid leprosy were reviewed and assessed in respect of the following features: the presence of an epithelioid cell granuloma; the full development or maturation of epithelioid cells (indicated by large cell size, large nucleus with prominent eosinophilic nucleolus), in at least some areas; the presence of giant cells; the number of large Langhans'-type giant cells; the number of lymphocytes in relation to the size of the granuloma, especially in the deep zone of the dermis, and their relationship to the granuloma; the presence or absence of a clear sub-epidermal zone; the erosion of the basal and squamous layers of the epidermis by granuloma (not just lymphocytic infiltration); the degree of nerve involvement (lymphocytic infiltration, Schwann cell proliferation, nerve enlargement, disorganization of structure, central caseation); the destruction of sweat glands.

The destruction of sweat glands appeared to be related to the envelopment of glands by a large tuberculoid granuloma, and was therefore dependent mainly on the size of the granuloma. There was usually no involvement of glands situated in normal dermis (unlike nerve involvement). It was at least as likely to be seen in BT as in TT lesions, and was not a very useful criterion for classification. The results of the analysis of the other histological features are summarized in Table 1.

It will be seen that there were 19 cases with $2+$ lymphocytes together with epithelioid cell granuloma, the lymphocytes encompassing the granuloma and not being situated within it. In 9 of these biopsies there were in some though not all areas compact nests of fully developed epithelioid cells which, since they are known to interdigitate, did not allow the infiltration of many lymphocytes between them (group 1). In the other 10 cases the epithelioid cells were few, immature and often dispersed with lymphocytes in between them. The histology was that of an indeterminate lesion with early tuberculoid 
features (group 2). None of the cases in groups 1 or 2 scored $2+$ for the LTT-associated features: involvement of nerve or epidermis, or numerous Langhans' giant cells. These features in fact were conspicuous by their near absence in most cases. The slight involvement of the nerves was surprising and could have presented a diagnostic hazard. In line with the lack of epidermal involvement there was often a narrow sub-epidermal clear zone, and in other cases the whole lesion, if small, was confined to the middle and deep zones of the dermis.

There were another 17 cases which scored $2+$ for one or other of the LTT-associated features, though never for all of them. None of these cases scored $2+$ for lymphocytes; some scored + , others only \pm (group 3 ). However, there were also 8 cases with mixed features, a score of $1+$ for lymphocytes and $1+$ for the features associated with a high LTT, but not $2+$ for either. These also are included in Table 1 (group 4).

\section{EVALUATION OF THE SUBGROUPS}

Data for a proper evaluation of the 4 subgroups was lacking, but there was evidence of a maximal immune response in groups 1 and 3. The lepromin reaction was graded as $3+$ in 4 out of 4 cases in these 2 groups. AFB were found in $0 / 9$ and $1 / 17$ cases in groups 1 and 3 respectively. Only 1 patient (group 3) was followed up without treatment, and he healed spontaneously. Group-1 patients all had solitary lesions. In group 3 the LTT is known to be maximal. ${ }^{9}$

The results for groups 2 and 4 were not quite so good. There were no lepromin results for group $2 ; 1$ case was recorded in group 4 as $3+$, another only $1+$. AFB were found in $3 / 10$ and in $3 / 8$ cases, respectively. One group- 2 patient was proved to be self-healing, but in another the infection was evidently spreading before he was put on treatment.

Small numbers of cases from all 4 of these subgroups were included in an immunoperoxidase study of skin lesions. Immunoglobulins, complement components, lysozyme and plasminogen were all present in greater amounts in all TT subgroups than in BT or BB lesions, despite the low bacterial load in TT and a general correlation of the inflammatory mediators with bacterial load from BT to LL. ${ }^{14}$

\section{DERIVATION OF THE SUBGROUPS}

The best clinical correlation obtained in group 1, the original TT group of the Ridley-Jopling classification, but the number of cases found was too small to constitute a useful group for classification purposes. They were all solitary lesions, and the patients were all free of reactional features, clinically and histologically. Destructive nerve lesions were not seen. This appeared, therefore, to be a primary group though it is not known whether or not the patients had passed through an indeterminate phase. 
Table 1

\begin{tabular}{|c|c|c|c|c|c|c|c|c|c|c|c|}
\hline $\begin{array}{l}\text { Sub- } \\
\text { group }\end{array}$ & $\begin{array}{l}\text { Probable } \\
\text { derivation }\end{array}$ & $\begin{array}{c}\text { No. of } \\
\text { cases }\end{array}$ & $\begin{array}{l}\text { Clinical } \\
\text { classifi- } \\
\text { cation }\end{array}$ & $\begin{array}{l}\text { Lympho- } \\
\text { cytes }\end{array}$ & $\begin{array}{l}\text { Develop- } \\
\text { ment } \\
\text { epitheloid } \\
\text { cells }\end{array}$ & $\begin{array}{c}\text { Langhans' } \\
\text { giant } \\
\text { cells }\end{array}$ & $\begin{array}{c}\text { Nerve } \\
\text { involve- } \\
\text { ment }\end{array}$ & $\begin{array}{l}\text { Erosion } \\
\text { epidermis }\end{array}$ & $\begin{array}{l}\text { Clear } \\
\text { SEZ }\end{array}$ & $\begin{array}{c}\text { Reactional } \\
\text { oedema }\end{array}$ & $\begin{array}{c}\mathrm{AFB} \pm \\
\text { No. } \\
\text { cases }\end{array}$ \\
\hline 1. & Primary & 9 & $\begin{array}{l}8 \mathrm{TT} \\
1 \text { mac-ans }\end{array}$ & ++ & ++ & $-1 \pm$ & \pm & - & $-1+$ & - & - \\
\hline 2. & $\begin{array}{l}\text { Post- } \\
\text { indeterminate }\end{array}$ & 10 & $\begin{array}{l}5 \mathrm{TT} \\
4 \mathrm{TT}-\mathrm{BT} \\
1 \mathrm{idt}\end{array}$ & ++ & $\pm /+$ & - & $\pm /+$ & - & $-1+$ & - & 3 \\
\hline 3. & Secondary & 17 & $\begin{array}{l}3 \text { TT } \\
7 \text { TT-BT } \\
7 \text { BT }\end{array}$ & $+/ \pm$ & $+1++$ & $-1++$ & $\pm /++$ & $-1++$ & $-/ \pm$ & $-1+$ & 1 \\
\hline 4. & Mixed & 8 & $\begin{array}{l}2 \mathrm{TT} \\
4 \mathrm{TT}-\mathrm{BT} \\
2 \mathrm{BT}\end{array}$ & + & $+/++$ & $-1+$ & $\pm /+$ & $-1+$ & $-/ \pm$ & $-/ \pm$ & 3 \\
\hline
\end{tabular}


Group-2 patients presented a slightly less homogeneous clinical picture though it was still strongly tuberculoid, predominantly TT though there was more than 1 lesion in some cases. Only 1 case was clinically indeterminate but the histology in all of them strongly suggested that they were post-indeterminate. The absence of reactional features was consistent with this. It could be that some of these cases would have evolved into group 1, but their evaluation (above) suggested that, as in indeterminate cases, the outcome was not completely predictable.

The majority of group 3 patients were clincally either TT-BT or BT, though a few were TT and solitary skin lesions were not unknown. The presence of reactional oedema in at least half the cases and a clinical history of reaction in some was in keeping with the strong LTT-associated histological features which are known to be associated with reactional or post-reactional states. $^{9,15}$ It is likely, therefore, that in this group of patients the disease evolved through a delayed recognition of bacterial antigen, which in many cases had already become disseminated. On recognition there was some degree of reaction or an overt explosion. In 1 patient with a quiescent solitary skin lesion and in another with several lesions there were associated nerve abscesses; and caseation in nerve bundles of the skin was not uncommon. Even though not all the patients had passed through a borderline phase, it was in some respects an evolved or secondary group comparable to LLs at the other end of the spectrum.

The derivation of the group 4 patients with mixed features is uncertain. Although there were only 8 of them the existence of this group, like that of the much larger BT group, seems to indicate that the distinction between the two forms of response only applies at the extreme immunological level.

\section{INCIDENCE OF THE SUBGROUPS}

There were marked geographical variations in the incidence of the two main forms of lesion. The lymphocytic type lesions (groups 1 and 2) were found in equatorial Africa, Papua New Guinea, Fiji, in some Eurasian patients, and there was one Indian maculo-anaesthetic (though some other patients of this type are probably low resistant $\mathrm{t}^{16}$ or $\mathrm{BT}$, or histologically indeterminate ${ }^{17}$ ) None were found among the large number of cases from Malaysia and Ethiopia.

The high LTT-associated lesions of group 3 and the mixed group 4 were found in patients from Malaysia, Ethiopia and Papua New Guinea, but not from equatorial Africa.

The incidence of the strong groups 1 and 3 together amounted to 26 cases out of about 1,500. When the slightly suspect groups 2 and 4 are included the total increased to 44, giving an overall incidence of about 3\%. Although the types of case varied geographically there were no obvious differences in total incidence in the areas from which material was received. There are, how- 
ever, reasons for thinking that the figure of $3 \%$ may be too low. It is lower than the $5.7 \%$ previously quoted, ${ }^{12}$ though the latter may be partly attributed to a higher incidence in early lesions some of which are no doubt self-healing. It may also be that lesions which are thought to be self-healing are less likely to be biopsied. Reacting cases which might have evolved as TT (type 3) were excluded. The main purpose of the more recent material received from Malaysia and Ethiopia was the study of drug resistance in mainly lepromatous patients, which would bias the results against tuberculoid. It seems reasonable, therefore, to accept the incidence in these areas as being between 3 and $6 \%$.

In addition to the TT cases there were about 15 cases that were intermediate between TT and BT, and perhaps more could have been found by careful searching, but the number was appreciably smaller than those included in the TT group.

\section{Conclusion}

Although the BT group is so much larger than the TT group it did not appear that there was a large gap in the spectrum between them. Even with a 5-group spectrum there are bound to be intermediate points between adjacent groups, but there does not appear to be any justification for making a special TT-BT group. TT, as it is considered here, seems to include most cases that can usefully be separated from BT, which is the 'normal' tuberculoid group.

The TT group is a small though not insignificant group of much theoretical interest. It is the infection on a knife edge, poised between progression and spontaneous healing, which is why it is uncommon.

At the highest level in the tuberculoid scale there were two fairly distinct forms. Although the immunological relationship between cell-mediated immunity and delayed hypersensitivity has not been clearly elucidated, it is difficult not to think that a measure of separation between these two lymphocytemediated functions is not the root cause of the different histological, clinical and geographical patterns observed here. It could be postulated that the distinction determines to some extent the manner of evolution of the infection, or perhaps it is determined partly by it. Truly immune people, who never develop lesions beyond the indeterminate stage, display only the lymphocytic immune process. Those who develop lesions lower down the spectrum display a less-well-developed mixed type of response, which may subsequently become enhanced if (and only if) there is an increase of delayed hypersensitivity.

The lyriphocyte-mediated groups 1 and 2 are primary TT in the sense that the patients have never passed through a borderline phase, and to this extent they are the counterpart of the LLp group at the other end of the spectrum. The delayed hypersensitivity group 3 is secondary TT, in the sense that it has evolved as a result of reactional processes, which often commence in the borderline part of the spectrum; it is therefore the counterpart of LLs. Thus 
the TT groups could be designated TTp and TTs but, unlike the LL subgroups, there is no evidence that primary and secondary TT equates with polar and subpolar performance. And the group 4 cases which are clearly sub-polar could be either primary or secondary.

\section{Acknowledgements}

I am most grateful to the many clinicians who have sent me specimens and kindly supplied clinical data, and in particular to Drs W H Jopling, A B G Laing, J M H Pearson, D A Russell and M F R Waters. Also to Dr D J Harman for giving me access to the biopsies and records of the Leprosy Study Centre.

\section{References}

1 Noussitou F. Some aspects of tuberculoid leprosy and chemotherapeutic trials. Acta Leprologica, 1979; no. 74: 1-32.

2 Souza Lima L, Souza Campos N. Quoted by Noussitou.

${ }^{3}$ Ridley DS, Jopling WH. The classification of leprosy according to immunity. A 5 group system. Int J Lepr, 1966; 34: 255-73.

4 Ridley DS. Histological classification and the immunological spectrum of leprosy. Bull Wld Hlth Org, 1974; 51: 451-65.

${ }^{5}$ Meyers WM, Heggie CD, Kay TL, Staple EM, Kvernes S. The Ridley-Jopling 5 group classification of leprosy - correlations of parameters of the classification in 1,429 leprosy patients. Int J Lepr, 1979; 47: 683-4.

6 Thomas J, Joseph M, Ramanujam K, Chacko CJG, Job CK. The histology of the Mitsuda reaction and its significance. Lepr Rev, 1980; 51: 329-39.

7 Myrvang B, Godal T, Ridley DS, Fröland SS, Song YK. Immune responsiveness to Mycobacterium leprae and other mycobacterial antigens throughout the clinical and histopathological spectrum of leprosy. Clin Exp Immunol, 1973; 14: 541-53.

8 Job CK, Chacko CJG, Taylor PM, Daniel M, Jesudian G. Evaluation of cell-mediated immunity in the histopathologic spectrum of leprosy using lymphocyte transformation test. Int J Lepr, 1976; 44: 256-66.

9 Bjune G, Barnetson R StC, Ridley DS, Kronvall G. Lymphocyte transformation test in leprosy; correlation of the response with inflammation of lesions. Clin Exp Immunol, 1976; 25: 85-94.

10 Bjune G. Variation of in vitro lymphocyte responses to $M$. leprae antigen in borderline tuberculoid leprosy patients. Int J Lepr, 1980; 48: 30-40.

11 Ridley DS. Hypersensitivity and immunity, reactions and classification. Lepr Rev, 1976; 47: $171-4$.

12 Ridley DS. The pathogenesis of the early skin lesion in leprosy. J Path 1973; 111: 191206.

13 Ridley DS. Skin Biopsy in Leprosy. Basel: Documenta Geigy 1977.

14 Ridley DS, Ridley MJ, Russell DF. An immunoperoxidase study of immunological factors in skin lesions across the spectrum of leprosy. Int J Lepr (in press).

15 Ridley DS, Radia KB. The histological course of reactions in borderline leprosy and their outcome. Int J Lepr, 1981;49: (in press).

16 Leiker DL. Low resistant tuberculoid leprosy. Int J Lepr, 1964; 32: 359-67.

17 Desikan KV. Flat lesions in leprosy. A reappraisal of the indeterminate type. Lepr India, $1975 ; 47: 291-4$. 